\title{
Análise das Questões de Biologia Celular nos Vestibulares da UEPG entre 2010 a 2016: Implicações para a Educação em Ciências e Biologia
}

\author{
Analysis of the questions in Cell Biology of the vestibular of UEPG \\ between 2010 to 2016: Implications for Science Education and Biology
}

\author{
Jussara Aline de Andrade (jussaraandrade1994@gmail.com) \\ Universidade Estadual de Ponta Grossa (UEPG) \\ Rodrigo Diego de Souza (professor.rodrigosouza@ gmail.com) \\ Centro de Ciências da Educação, Universidade Federal de Santa Catarina (MEN/CED/UFSC).
}

Resumo: Os vestibulares nas Universidades Públicas consistem num dos maiores mecanismos de exclusão social, na medida em que selecionam quem pode ou não ter o direito à Educação Superior Pública e Gratuita, frente a isto e a função social da Educação em Ciências e Biologia, neste artigo, analisam-se as questões de Biologia Celular dos vestibulares da UEPG, no período entre 2010 a 2016, com o intuito de identificar as concepções que emergem destas questões e suas implicações para a Educação em Ciências e Biologia. Foram selecionadas e analisadas 51 questões. Com a análise qualitativa e a utilização das categorias das visões deformadas do trabalho científico, propostas por Pérez et al (2001), constatou-se que as questões não trazem uma visão crítica da ciência e de seus desdobramentos para a Educação, que são estritamente específicas e não problematizam as questões sociais mais amplas nas quais os conhecimentos acerca dos organismos vivos são produzidos, ou seja, apresentam a pseudoneutralidade da ciência. Considerando-se que as provas dos vestibulares muitas vezes determinam a construção dos currículos nas escolas, indiretamente, numa espécie de ação-reação, os estudantes cada vez mais tem acesso a conhecimentos fragmentados e pautados na memorização para a aprovação em vestibulares.

Palavras-chave: Avaliação; Biologia Celular; Educação em Ciências; Ensino de Biologia; Vestibular.

Abstract: The entrance exams in the Public Universities consist of mechanisms of social exclusion, since they select who can or not have the right to Public and Free Superior Education. In view of the social function of Science and Biology Education, in this article, we analyze the Cell Biology issues of the UEPG entrance exam, between 2010 and 2016, in order to identify the conceptions that emerge from these issues and their implications for Education in Science and Biology. We selected and analyzed 51 questions. With the qualitative analysis and the use of the categories of deformed visions of scientific work, proposed by Pérez et al (2001), it was found that the issues do not have a critical view of science and are strictly specific, and do not problematize social issues in the production of knowledge about living organisms, considering that evidence often determines the construction of curricula in schools, indirectly, in a kind of action-reaction, students increasingly have access to fragmented knowledge and patterned in memorization for approval in college entrance exams. 
Keywords: Evaluation; Cell Biology; Science Education; Biology Teaching; Entrance exam.

\section{Introdução}

É importante compreender a biologia como um corpo de conhecimentos sistematizado a qual pode ser observada em centenas de coisas que acontecem e que são visualizadas no dia a dia, podendo relacioná-las com o corpo, com os animais, com as plantas, com as doenças, os vírus, bactérias; nessa direção a importância da abordagem de biologia celular nas práticas de ensino é essencial, mas para os alunos pode muitas vezes ser difícil assimilar conceitos e entender de fato o que cada assunto quer dizer.

A escola recebe cobranças e exige o bom desempenho dos alunos, porém, isso vai depender de uma série de fatores estruturais e sociais da escola. Brandalise (2011) fala que é exigido das escolas bons desempenhos, pois a escola é imprescindível à sociedade atual, "a complexidade inerente aos processos avaliativos torna evidente a exigência com os resultados ao desempenho dos alunos e com o desempenho das escolas" (BRANDALISE, 2011, p. 316). A autora também diz que a avaliação deve ter uma perspectiva muito mais ampliada englobando a todos os elementos em torno do ensino e aprendizagem.

Para Costa-Beber e Maldaner (2015) é considerável o fato que as características dos processos seletivos para o ingresso ao ensino superior, influenciam o currículo escolar e que isso parece ser o objetivo central de muitas escolas.

Atrelado a isto, os vestibulares nas Universidades Públicas também consistem num dos maiores mecanismos de exclusão social, na medida em que selecionam que pode ou não ter o direito à Educação Superior Pública e Gratuita e, além disso, determinam a construção dos currículos do Ensino Médio; como também apontam D’Ávila e Soares (2003, p. 108), quando dizem:

$\mathrm{Na}$ realidade brasileira, muito mais do que a porta de entrada, o vestibular representa a porta de saída, isto é, a não entrada de aproximadamente $90 \%$ dos candidatos não aprovados anualmente para o ingresso nas universidades federais (Soares-Lucchiari, 1993). As provas dos vestibulares têm determinado a organização do ensino nas escolas fundamentais e principalmente, nas escolas de ensino médio no sentido da aprendizagem ser dissociada da real necessidade dos estudantes, enfatizando o ensino através de "macetes" e dicas para melhor responder as questões do vestibular. 
Desta forma, este artigo resultado de um Trabalho de Conclusão de Curso de Licenciatura em Ciências Biológicas, emerge das indagações que permearam a primeira autora no decorrer dos Estágios Supervisionados e demais atividades desenvolvidas no curso, associadas às possíveis dificuldades que os alunos expressam em compreender o conteúdo de Biologia Celular no Ensino Médio, e com os termos técnicos existentes no vestibular, que muitas vezes não se apresentam na escola, fica difícil concluir com êxito uma prova de vestibular.

Optou-se então, por analisar as questões de Biologia Celular dos vestibulares da UEPG, no período do ano de 2010 a 2016, com o intuito de identificar as concepções que emergem destas questões, suas implicações para a Educação em Ciências e Biologia, utilizando-se também das categorias das visões deformadas do trabalho científico, propostas por Pérez et al (2001), para a análise.

\section{Educação e Avaliação em Ciências e Biologia: Algumas Reflexões}

Como cita Lederman (1992), Khalick e Lederman (2000) apud Carvalho (2004), não é aceitável que para as próximas gerações tenha-se uma ciência de conteúdos prontos e acabados, pois, o entendimento da ciência passou a ser um dos principais objetivos da educação. Para Carvalho, (2004) o ensino deve levar os estudantes a construir conceitos dando a oportunidade de aprenderem a argumentar em vez lhes darem respostas prontas ou impor-lhes uma visão fechada das ciências.

Krasilchik (2008) ressalta que os alunos memorizam as informações de forma desconexa para atender as mínimas exigências escolares. Bizzo (2002) compartilha a ideia de que o conhecimento científico é preferencialmente o abstrato e simbólico, o que dificulta entender os significados que acabam muitas vezes sendo arbitrários.

Entretanto, os objetos de estudo da biologia permeiam nosso cotidiano, conforme Marandino, Selles e Ferreira (2009) sinalizam, pois "os conhecimentos das ciências estão em nosso cotidiano, presentes nos desenhos animados, nas propagandas, nas novelas, nos produtos que consumimos, por meio de imagens, termos, conceitos ideias e representações”, então porque muitas vezes o conhecimento escolar acerca da biologia parece muitas vezes tão complexo? 
Associado a isto, os alunos às vezes apresentam-se desmotivados para aprender Biologia por conter conteúdos abstratos e específicos, e isso dificulta relacionar o conteúdo com a realidade, fazendo com que o aluno não entenda o porquê de aprender aquilo (BARBOSA et. al., 2016).

Para Martins e Braga (1999) os professores de biologia criticam lacunas no Ensino de Biologia, quanto à ausência de atividades experimentais em sala de aula, e a ênfase à memorização, tornando-se totalmente acadêmico e desvinculado das implicações sociais.

No entanto, têm-se pesquisas que se preocupam com diferentes metodologias que possibilitem um aprendizado diferenciado, como aponta Pedrancini et al (2007, p. 300):

\begin{abstract}
Tomando como referência o ensino de Biologia, pesquisas sobre a formação de conceitos têm demonstrado que estudantes da etapa final da educação básica apresentam dificuldades na construção do pensamento biológico, mantendo ideias alternativas em relação aos conteúdos básicos desta disciplina, tratados em diferentes níveis de complexidade no ensino fundamental e médio. (BASTOS, 1992; CABALLER e GIMÉNEZ, 1993; GIORDAN e VECCHI, 1996 apud PEDRANCINI et. al., 2007, p.300).
\end{abstract}

Nesta direção, a Biologia Celular é um conteúdo que para muitos é abstrato, porém, é de grande importância para o aprendizado do aluno, pois a célula é um dos principais conceitos na construção do conhecimento biológico (HECK, HERMEL, 2013).

\footnotetext{
Tratando-se de célula, vale ressaltar que, por ser microscópica, sua presença e observação não é tão óbvia para os alunos de Ensino Médio. Mesmo com a utilização de inúmeros livros de Biologia, que contém representações em formas de fotografia, desenhos e esquemas representando toda a gama imaginável de escalas, secções e idealizações dos seres vivos, de suas estruturas e seus componentes, os alunos possuem dificuldades na hora de interpretar ou desenhar suas observações. (TEIXEIRA et. al., 2006, p.1).
}

Barbosa et. al. (2016) acredita que a citologia é fundamental para o entendimento dos seres vivos, as suas funções e complexidade, o que possibilita ao aluno fazer associações com outros conteúdos da disciplina de Biologia, obtendo a interação necessária.

Teixeira et. al. (2006) cita que "segundo os PCNs (2003), a ciência é pouco utilizada como instrumento para interpretar a realidade ou para nela intervir e os conhecimentos científicos acabam sendo abordados de modo descontextualizado". 
Articulado ao conhecimento descontextualizado e as dificuldades referentes ao ensino e a aprendizagem de Biologia Celular, o modelo dos Vestibulares, enquanto instrumento de seleção muitas vezes potencializada o modelo tradicional e fragmentado de ensino.

O vestibular é na maioria das vezes temido e gera conflitos no ambiente escolar, de um lado candidatos a vestibulares querendo a inserção no currículo dos conteúdos e livros cobrados nos vestibulares, e por outro lado aqueles que não pretendem ingressar no ensino superior discordam da cobrança excessiva (BELTRÃO, 2014).

A concorrência é muito grande entre os alunos e a falta de direcionamento e informação de muitas escolas públicas fazem com que muitos alunos não queiram entrar para um curso superior (CASTRO, 2001).

Quanto à avaliação, Beltrão (2014) e Brandalise (2015), apresentam as seguintes reflexões:

\begin{abstract}
As avaliações externas são importantes e necessárias para se implementar e acompanhar políticas públicas em educação, desde de que desenvolvidas com metodologias adequadas que possibilitem o diálogo com as avaliações institucionais promovidas pelas unidades escolares, oferecendo informações interessantes para toda a comunidade. (BELTRÃO, 2014, p.822).

O real significado da avaliação na educação está em fortalecer o movimento que leva à emancipação social e à democratização da sociedade, podendo, nessa perspectiva, contribuir para entender a complexa trama em que as políticas educacionais são produzidas e como elas se materializam no cotidiano da escola. (BRANDALISE, 2015 p. 61).
\end{abstract}

Relacionado a isto "no Brasil diversas avaliações tem sido implementadas, com objetivo principal de fornecer indicadores de qualidade da educação brasileira em todos os seus níveis de ensino" (ARAÚJO, 2011 p. 1).

Entretanto as Avaliações enquanto indicadores de qualidade, muitas vezes mascaram objetivos implícitos e explícitos, e não apenas nas Avaliações Nacionais, como também nos Vestibulares que muitas vezes mascaram um real sentido de qualidade, quando se torna critério para estabelecer que Colégios e Escolas sejam melhores por meio de rankings de aprovação nos vestibulares.

Tendo em vista as reflexões apresentadas, buscou-se analisar as questões de Biologia Celular dos vestibulares da UEPG, 2010 a 2016, com intuito de identificar as 
concepções que emergem destas questões e suas implicações para a Educação em Ciências e Biologia.

\section{Aspectos Metodológicos da Pesquisa}

Esta pesquisa caracteriza-se como uma pesquisa documental com análise qualitativa. Conforme Minayo (2001, p.21) indica, “a pesquisa qualitativa responde a questões muito particulares. Ela se preocupa, nas ciências sociais, com um nível de realidade que não pode ser quantificado", o movimento de análise dos dados foi subsidiado pelas categorias das visões deformadas do trabalho científico, propostas por Pérez et al (2001).

Nesse sentido, buscou-se analisar nesta pesquisa as questões de Biologia Celular dos vestibulares da Universidade Estadual de Ponta Grossa (UEPG), no período entre 2010 a 2016, com o intuito de identificar as concepções que emergem destas questões e suas implicações para a Educação em Ciências e Biologia.

As provas dos vestibulares da UEPG estão disponíveis para download nos arquivos online da Universidade Estadual de Ponta Grossa, disponível no site http://cps.uepg.br/inicio/index.php/vestibular/anteriores.

A Universidade realiza os vestibulares duas vezes ao ano, e por isso, foram coletadas as questões de todas as edições do vestibular que ocorreram no período de 2010 a 2016, das provas de Conhecimentos Gerais e de Conhecimentos Específicos que remetessem a Biologia Celular, totalizando-se 51 questões, as quais foram todas selecionadas e analisadas.

As questões analisadas são no formato de somatória, uma das características dos vestibulares da UEPG, com quatro opções de respostas nas questões gerais e cinco opções de respostas nas provas específicas, onde os candidatos podem julgar mais de uma resposta sendo a correta.

Constatou-se que as questões sobre Biologia Celular estão sempre presentes nas provas, o que mostra a importância do conteúdo. A partir da análise das questões elas foram agrupadas por similaridade.

Optou-se como critério para análise da amostra coletada, a inclusão das questões que envolvessem a Biologia Celular direta e indiretamente, como o conteúdo sobre 
tecidos, por exemplo, e outros assuntos como Genética e Embriologia não foram incluídos embora apresentem relações com o componente curricular de Biologia Celular.

Depois de selecionadas as 51 questões e organizadas de acordo com o enfoque temático/conteúdos relacionado à Biologia Celular, elas foram analisadas e categorizadas de acordo com as visões deformadas do trabalho científico, propostas por Pérez et. al. (2001), sendo as seguintes categorias:

a) Concepção empírico-indutivista e ateórico;

b) Visão rígida (algorítmica, exata e infalível);

c) Visão aproblemática e ahistórica;

d) Visão socialmente neutra da ciência.

\section{A Biologia Celular nos Vestibulares da UEPG}

A partir da coleta das questões de Biologia Celular dos vestibulares da UEPG, conseguiu-se um total de 51 questões. Essas questões foram encontradas em vestibulares de inverno e de verão da UEPG, conforme o gráfico 1 apresenta:

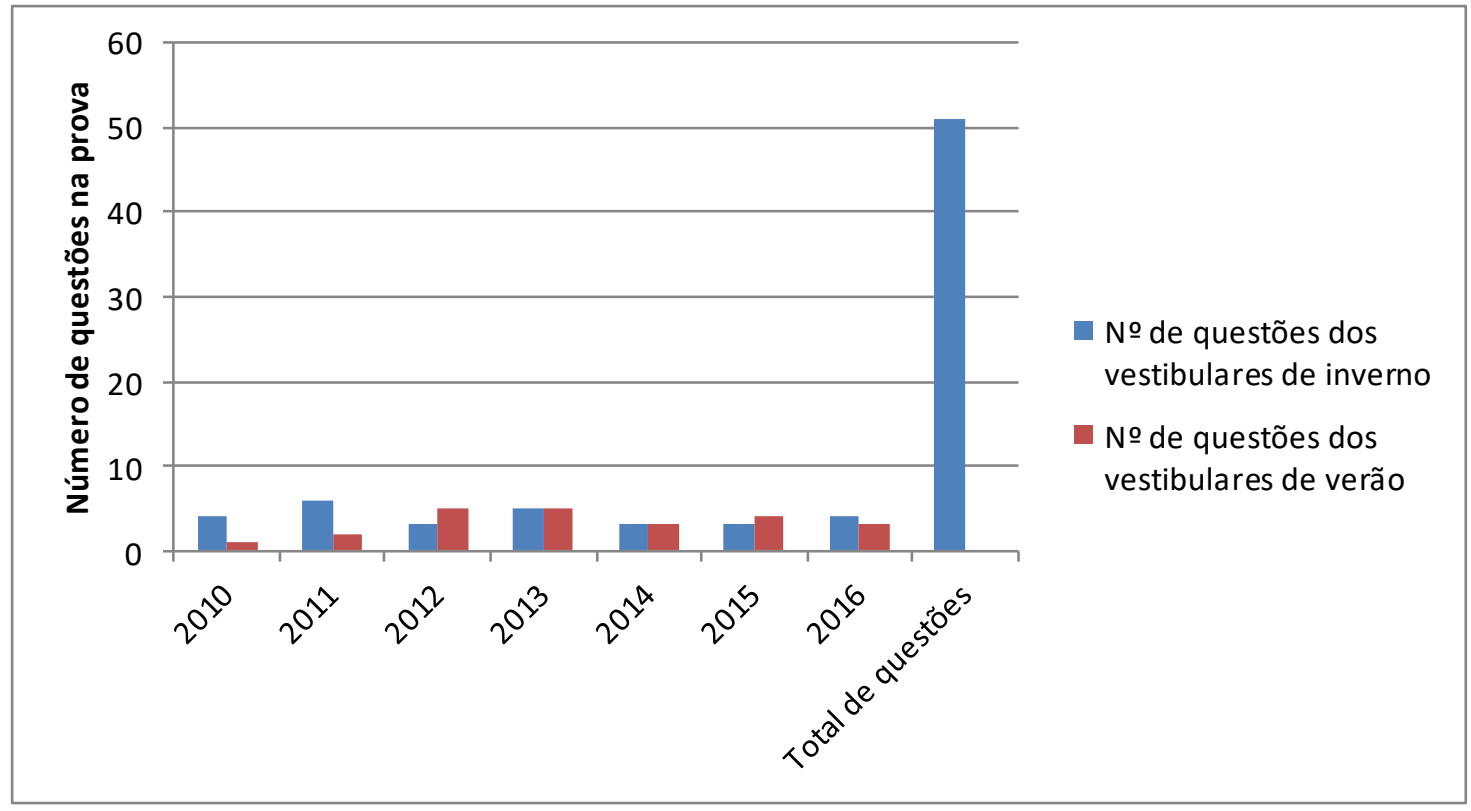

Gráfico 1 - Total de Questões de Biologia Celular nos Vestibulares da UEPG, 2010-2016. Fonte: Elaboração dos Pesquisadores a partir dos dados disponibilizados no site da UEPG. 
Observa-se que nos anos de 2010, 2011 e 2016 os vestibulares de inverno abordaram mais questões de Biologia Celular do que o vestibular de verão, em 2012 e 2015 houve maior número de questões nos vestibulares de verão e em 2013 as questões estavam em mesma proporção tanto para o vestibular de inverno, quanto para o de verão, em 2014 observa-se que também se encontra o mesmo número de questões para os dois concursos.

Do total dessas questões observou-se uma maior quantidade de alguns temas, as quais foram agrupadas por similaridades por temas, como o Gráfico 2 apresenta:

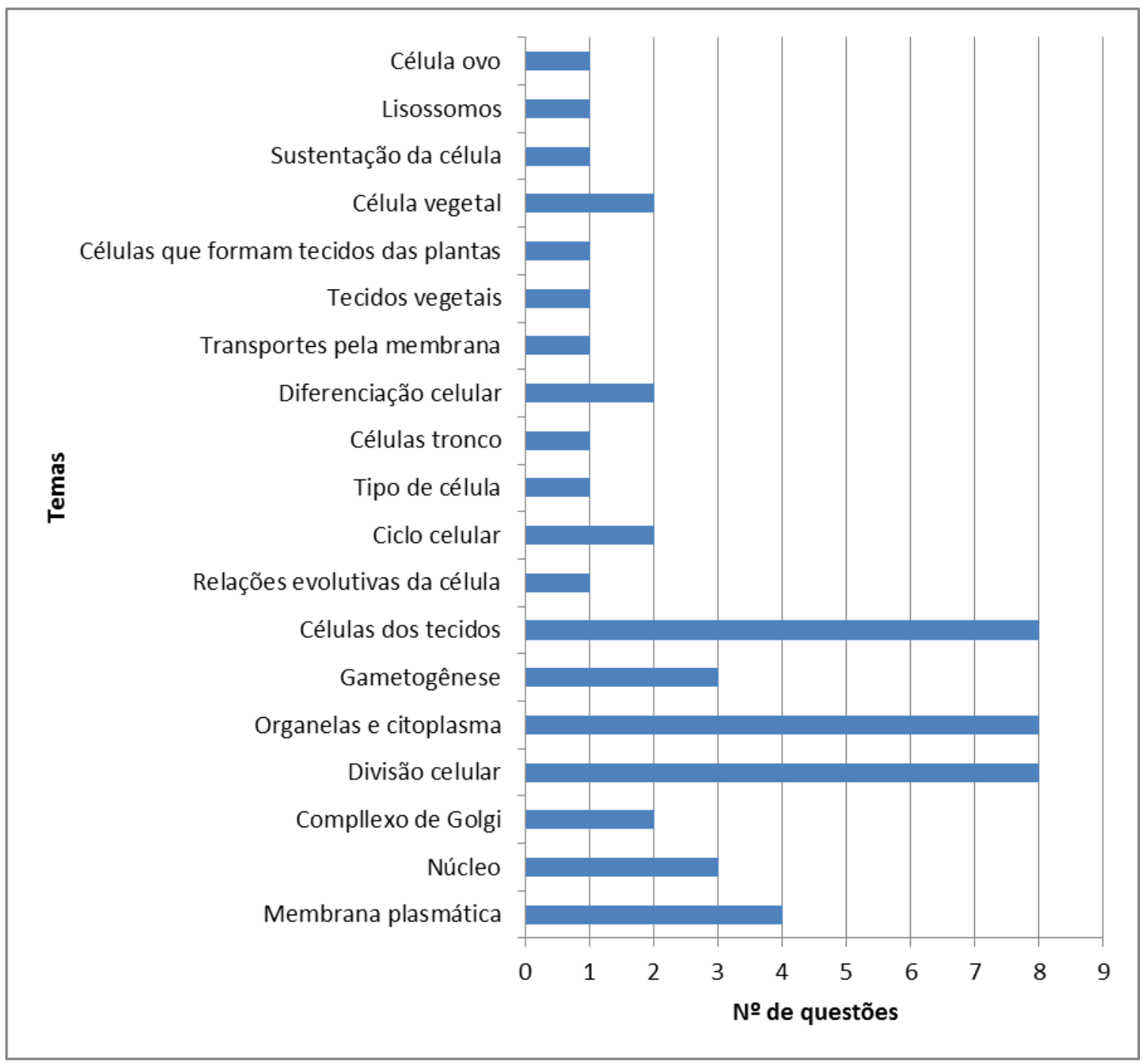

Gráfico 2 - Organização das Questões de Biologia Celular por temas.

Fonte: Elaboração dos Pesquisadores a partir dos dados disponibilizados no site da UEPG. 
Constatam-se mais questões referentes aos temas de divisão celular, organelas e citoplasma e referente às células dos tecidos. Temas como membrana plasmática, núcleo, complexo de golgi, gametogênese, ciclo celular, diferenciação celular e célula vegetal aparecem em algumas provas, mas, não com tanta frequência como as citadas anteriormente.

Já os temas: célula ovo, lisossomos, sustentação da célula, células que formam tecidos das plantas, tecidos vegetais, transportes pela membrana, células tronco, questões referentes ao tipo de células e relações evolutivas das células são as que menos aparecem, contendo apenas uma questão de cada em todas as provas, isso pode ser pelo fato de que o nível de complexidade de estudo desses temas seja maior.

A partir disso, começou-se analisar o conteúdo e a organização do conhecimento produzido nas Ciências Biológicas, em especial a Biologia Celular, no modelo de educação e de processo educativo que se dá a partir dessas questões.

Nessa direção, utilizou-se como categorias, as visões deformadas do trabalho científico, propostas por Pérez et. al. (2001), utilizando-as como categorias para agrupamento e análise das questões selecionadas, sendo as seguintes categorias:

a) Concepção empírico-indutivista e ateórico;

b) Visão rígida (algorítmica, exata e infalível);

c) Visão aproblemática e ahistórica;

d) Visão socialmente neutra da ciência.

Observa-se que todas as 51 questões estão alinhadas às concepções deformadas do trabalho científico propostas por Pérez et. al. (2001). Apresentam-se no Quadro 1, abaixo, algumas das questões analisadas:

Quadro 1: Exemplo de Questão.

Questão 1: Considerando os processos de mitose e meiose, assinale o que for correto.

01) Nos processos cancerígenos, o tumor é decorrente de divisões descontroladas das células por meio da meiose, visto que novas combinações genéticas podem levar ao surgimento de mutações.

02) Nos animais, a meiose ocorre durante a produção de gametas e, nos vegetais, a meiose é responsável pela formação dos esporos. Em organismos diploides, os gametas e os esporos são haploides.

04) Na meiose, o evento de crossing-over ou recombinação permite trocas de segmentos entre os cromossomos homólogos, fazendo surgir novas combinações genéticas.

08) Na fase de telófase mitótica, pode-se observar claramente os cromossomos ao microscópio óptico, pois os mesmos encontram-se em seu maior grau de compactação e localizados na região equatorial da célula.

16) Na citocinese de uma célula animal, ocorre o estrangulamento da região equatorial causado por um anel de filamentos contráteis de moléculas de actina e miosina, fato que não ocorre nas células vegetais. 
Questão 2: Com relação à membrana plasmática, assinale o que for correto.

01) Por meio da fagocitose, a célula emite expansões do citoplasma (pseudópodes), as quais envolvem a partícula a ser englobada e a coloca em uma cavidade no interior da célula, denominada de fagossomo.

02) Os protozoários são exemplos de organismos que utilizam a fagocitose em seu processo de alimentação, já nos vertebrados, esse processo é utilizado por algumas células de defesa do organismo contra corpos estranhos.

04) Restos de digestão intracelular podem ser eliminados da célula por meio da pinocitose, quando pequenas bolsas citoplasmáticas (pinossomos) são formadas e expelem para a corrente sanguínea o material não utilizado pela célula.

08) O glicocálice (ou glicocálix) trata-se de um envoltório externo à membrana de células vegetais, constituído por algumas proteínas que formam uma malha protetora, as quais fornecem resistência a esse tipo celular.

16) As microvilosidades são especializações da membrana plasmática, presentes em células do intestino, que funcionam no processo de adesão e comunicação entre as células.

Questão 3: As células-tronco são aquelas com potencial de formar diferentes tecidos. Com relação a esses tipos celulares, assinale o que for correto.

01) Existem dois tipos de células-tronco: as embrionárias e as adultas.

02) Os cientistas, em alguns países em que a legislação permite, utilizam as células-tronco embrionárias que se desenvolvem a partir de óvulos fertilizados in vitro, oriundos de clínicas de fertilização.

04) O uso das células-tronco ainda está apenas em fase de experimentação, não sendo ainda relatada nenhuma utilização in vivo.

08) As células do cordão umbilical congeladas após o parto podem ser reimplantadas no indivíduo, em algumas situações, caso o mesmo sofra algum dano, sem o risco de rejeição, pois essas células provêm do próprio paciente.

16) Medula óssea e cordão umbilical são locais onde pode-se encontrar as células-tronco adultas.

Questão 3: Durante a vida de um animal, as divisões celulares são rigorosamente controladas, de modo a garantir o bom funcionamento do organismo. Entretanto, podem ocorrer alterações genéticas que danificam o sistema de controle da divisão celular, levando a célula a crescer e se multiplicar sem necessidade, podendo gerar um tumor. Com relação ao controle do ciclo celular e geração de tumores em humanos, assinale o que for correto.

01) Os sarcomas são tumores provenientes de células originadas no ectoderma ou no endoderma.

02) No tumor malígno, as células alteradas são capazes de migrar e invadir tecidos vizinhos, podendo atingir, por meio da circulação sanguínea e linfática, diversas regiões do corpo, onde originam novos tumores.

04) Na metástase, as células tumorais malígnas se espalham e se estabelecem em outras áreas do corpo, formando novos tumores.

08) Se um tumor é constituído por células que ficam restritas ao local onde surgiram, geralmente ele não causa maiores problemas ao organismo, sendo, por isso, denominado tumor benigno.

Questão 4: A respeito dos elementos constituintes de uma célula eucarionte, denominados organelas, assinale o que for correto.

01) Observada ao microscópico óptico, o citoplasma da célula eucarionte revela muito pouco. Vê-se um material gelatinoso, o hialoplasma, no qual se reconhecem as estruturas mitocôndrias, cloroplastos e sistema golgiense.

02) Ao microscópio eletrônico, observa-se no hialoplasma eucarionte uma rede de finas membranas lipoprotéicas, que inclui o retículo endoplasmático e o sistema golgiense. Mitocôndrias, cloroplastos, lisossomos e peroxissomos são também envolvidos por membranas da mesma natureza.

04) Descobriu-se, recentemente, no hialoplasma dos eucariontes, a presença de finos tubos e filamentos de proteínas, em conjunto, chamados de citoesqueleto, que parece ser responsável por vários movimentos da célula e por manter sua forma.

08) Quimicamente, o hialoplasma é constituído de água e moléculas de proteína, formando uma dispersão denominada paraplasma.

Questão 5: Com relação às células, assinale o que for correto.

01) A célula da bactéria é mais simples do que a célula dos eucariotos. A célula procariota é caracterizada pela ausência de uma membrana envolvendo o seu

material genético, não havendo então a presença de um núcleo individualizado. 
02) A energia celular é proveniente das mitocôndrias, organelas responsáveis pela digestão de partículas no interior das células.

04) Os lisossomos são pequenos vacúolos que têm por função armazenar substâncias tóxicas às células e excretá-las ao meio extracelular.

08) Os centríolos são organelas localizadas próximo ao centro das células, proporcionado a nutrição necessária ao funcionamento celular.

16) O retículo endoplasmático é chamado de rugoso quando está associado aos ribossomos, tendo como função a síntese de proteínas. Já o retículo

endoplasmático liso é aquele livre dos ribossomos.

Fonte: Elaboração dos Pesquisadores a partir dos dados disponibilizados no site da UEPG.

As concepções que balizam a disposição e a organização dos conteúdos de Biologia Celular nas questões supracitadas sugerem uma visão de ciência exata e infalível, sem erros, na qual os alunos não precisariam entender os processos biológicos em uma abordagem evolutiva, histórica, em movimento e construção coletiva de conhecimentos, mas apenas a memorização de conteúdos de forma descontextualizada.

Além destes aspectos, Pérez et al (2001) também aponta que esta uma visão, até mesmo dogmática e cristalizada da ciência é bastante difundida entre os professores, que se referem ao método científico como sequências de etapas definidas, e muitas vezes como um método único.

Articulando-se a isto, as questões ao abordarem os conceitos apenas neles mesmos, de forma simplificada, caracterizam a ciência de modo ahistórico e aproblemático, ou seja, as questões não direcionam para uma análise crítica dos conceitos biológicos, da construção histórico-conceitual destes conceitos, e das relações que estes conhecimentos estabelecem com o cotidiano dos discentes e com o avanço científico e tecnológico vivenciado na contemporaneidade, o qual perpassa e tem, nos conteúdos da grande área de Ciências Biológicas, forte expressão.

Desta forma, não se fazem referência aos problemas que estão na origem da construção de tais conhecimentos. Ignora-se a história e teorias científicas para a construção do conhecimento, um conhecimento pronto e acabado, liofilizado, que corrobora para o aumento das lacunas acerca das aprendizagens em torno da origem e da possibilidade do conhecimento e não permitem conhecer as limitações da ciência (PEREZ et. al., 2001).

Evidencia-se também que, as questões analisadas ao emergir dos vestibulares de uma Universidade Pública, também corroboram para as reflexões acerca dos modos 
como esta prova de ingresso ao Ensino Superior também molda indiretamente a organização curricular do Ensino Médio.

Indiretamente, os vestibulares também conformam a organização curricular das escolas de Educação Básica - embora estejam alinhadas aos Documentos Oficiais Nacionais e Estaduais que regulamentam os currículos - prepara os adolescentes e jovens para os vestibulares, as práticas pedagógicas recebem outros contornos com o intento de alinhar o ensino e o estudo às exigências dos vestibulares.

Numa forma de ação-reação, os estudantes cada vez mais tem acesso a conhecimentos fragmentados, pautados na memorização para a aprovação em vestibulares.

Desse modo, observa-se que as lacunas referentes aos conteúdos esvaziados de crítica e recheados de memorização para "aprovação" nos vestibulares, implica na não aprendizagem e apropriação dos conteúdos de Biologia Celular para uma leitura crítica da realidade e formação crítica dos adolescentes e jovens, e determina indiretamente a organização dos currículos das escolas, muitas vezes alinhadas aos objetivos dos vestibulares.

\section{Considerações Finais}

Conclui-se que as questões analisadas são estritamente específicas e não problematizam as questões sociais mais amplas nas quais os conhecimentos acerca dos organismos vivos são produzidos, ou seja, apresentam a pseudoneutralidade da ciência; aspectos estes que tem desdobramentos na Educação em Ciências e Biologia.

As questões não trazem uma problematização dos conteúdos, todas tem o mesmo padrão de objetividade, considerando-se a memorização dos conteúdos selecionados.

Os vestibulandos não conseguem mostrar uma visão crítica a partir disto, é a famosa "decoreba" em que precisam estudar uma grande quantidade de conteúdos específicos, para que se consiga resolver a prova, e conquistar uma vaga na Universidade, e ao mesmo tempo, alinhada ao 'mercado dos cursinhos' preparatórios para os vestibulares, com certa determinação indireta da organização curricular das escolas, tendo em vista a aprovação dos alunos e alunas. 
As questões não possibilitam identificar a formação de sujeitos críticos, que compreendam a dimensão multifatorial (histórica, problematizadora, social, política, cultural, entre outras) que abarcam as Ciências Biológicas, de modo específico a Biologia Celular. Este artigo não esgota as discussões acerca da temática, mas apresenta reflexões preliminares que poderão ser aprofundadas em trabalhos futuros.

\section{Referências bibliográficas}

Avaliação institucional na escola pública: os (des)caminhos de uma política educacional. Educar em Revista, Curitiba, Brasil, Edição Especial n. 1/2015. Disponível em < http://www.scielo.br/scielo.php?pid=S0104$40602015000500055 \&$ script=sci_abstract\&tlng=pt $>$ Acesso em 25 jan. 2019.

ARAÚJO, M. L. H. S. Avaliação internacional: concepções inerentes ao PISA e seus resultados no Brasil. Atas do $\mathbf{2 6}^{\circ}$ Seminário Nacional da Associação Nacional de Política e Administração da Educação. 2011. Disponível em <http://www.anpae.org.br/simposio26/1comunicacoes/MaLourdesAraujoComunicacaoOral-int.pdf> Acesso em 25 jan. 2019.

BARBOSA, N. F. M. V.; SOUZA, C. J. B.; RODRIGUES, T. C.; ARAÚJO, R. L. N. Dificuldades no processo de ensino-aprendizagem de Citologia dos discentes da $1^{\mathrm{a}}$ série do Ensino Médio da Escola Estadual de Ensino Médio Oswaldo Pessoa - João Pessoa, PB. Atas do Congresso Nacional de Pesquisa e Ensino de Ciências. João Pessoa, 2016. Disponível em <http://www.editorarealize.com.br/revistas/conapesc/trabalhos/TRABALHO_EV058_ MD1_SA93_ID1398_05052016142650.pdf> Acesso em 25 jan. 2019.

BELTRÃO, J. A. A Educação Física na escola do vestibular: as possíveis implicações do ENEM. p. 822 e 824, Porto Alegre, 2014.

BIZZO, N. Ciências: fácil ou difícil? São Paulo, $2^{\mathrm{a}}$ ed., 2002.

BRANDALISE, M. Â. T. Avaliação institucional da escola: conceitos, contextos e práticas. P. 318, Ponta Grossa-PR, 2011.

CARVAlHO, A. M. P. [org]. Ensino de ciências: unindo a pesquisa e a prática. São. Paulo: Pioneira Thomson, 2004.

CASTRO, C. M. Educação superior e equidade: inocente ou culpada? Ensaio: avaliação de políticas públicas em educação. Rio de Janeiro, v. 9, n. 30, p. 110, 2001. Disponível em <http://www.scielo.br/scielo.php?script=sci_nlinks\&ref=000160\&pid=S0104$4036201200020000600006 \& \operatorname{lng}=$ pt $>$ Acesso em 25 jan. 2019.

COSTA-BEBER, L. B.; MALDANER, O. A. Um Estudo sobre as Características das Provas do Novo ENEM: Um Olhar para as Questões que Envolvem Conhecimentos Químicos. Química nova na escola. São Paulo-SP, BR. Vol. 37, N 1, p. 44-52, 2015. 
Disponível em < http://qnesc.sbq.org.br/online/qnesc37_1/08-EQF-49-13.pdf> Acesso em 25 jan. 2019.

D'AVILA, G. T.; SOARES, D. H. P. Vestibular: fatores geradores de ansiedade na cena da prova. Revista da ABOP, 4(1), 105-116. 2003. Disponível em

$<$ http://pepsic.bvsalud.org/scielo.php?script=sci_arttext\&pid=S1679-

$33902003000100010>$ Acesso em 25 jan. 2019.

HECK , C. M.; HERMEL E. E. S. A célula em imagens: uma análise dos livros didáticos de ciências do ensino fundamental. Anais do $3^{\circ}$ SEPE e $3^{\text {a }}$ Jornada de Iniciação Científica. UFFS, Cerro Largo, p. 1, 2013. Disponível em $<$ https://periodicos.uffs.edu.br/index.php/SEPE-UFFS/article/view/537/150> Acesso em 25 jan. 2019.

KRASILCHIK, M. Prática de ensino de biologia. São Paulo, $4^{a}$ ed. p. 11, 2008.

MARANDINO, M; SELLES, S. E; FERREIRA, M. S. Ensino de Biologia: Histórias práticas em diferentes espaços educativos. $1^{a}$ edição, p. 135, São Paulo, 2009.

MARTINS, C. M. C.; BRAGA, S. A. M. As ideias dos estudantes, o ensino de biologia vegetal e o vestibular da UFMG. Atas do II Encontro Nacional de Pesquisa em Educação em Ciências. São Paulo, 1999. Disponível em $<$ http://www.nutes.ufrj.br/abrapec/iienpec/Dados/trabalhos/G10.pdf > Acesso em 25 jan. 2019.

MINAYO, M. C. S. Pesquisa Social: Teoria, método e criatividade. São Paulo: Vozes. $18^{\mathrm{a}}$ ed. 2001.

PEDRANCINI, V. D.; CORAZZA-NUNES, M. J.; GALUCH, T. B.; MOREIRA, A. L. O. R.; RIBEIRO, A. C. Ensino e aprendizagem de Biologia no ensino médio e a apropriação do saber científico e biotecnológico. Revista Electrónica de Enseñanza de las Ciências. Vol. 6, N² 2, 299-309, 2007. Disponível em <http://reec.webs.uvigo.es/volumenes/volumen6/ART5_Vol6_N2.pdf> Acesso em 25 jan. 2019.

PÉREZ, D. G.; MONTORO, I. F.; ALÍS, J. C.; CACHAPUZ, A.; PRAIA, J. Para uma Imagem não Deformada do Trabalho Científico. Revista Ciência \& Educação. Bauru, v.7, n.2, p.125-153, 2001. Disponível em <http://www.scielo.br/pdf/ciedu/v7n2/01.pdf> Acesso em 25 jan. 2019.

TEIXEIRA, J. M; LIMA, B. A; FAVETTA, L. R. A. O conceito de célula investigado numa sala de aula de Ensino Médio: um Estudo de Caso. Anais da $4^{\text {a }}$ Mostra de Acadêmica UNIMEP. 2006. Disponível em <http://www.unimep.br/phpg/mostraacademica/anais/4mostra/pdfs/229.pdf> Acesso em 25 jan. 2019. 